\title{
Local Research on Urban Leisure From the Perspective of Emotional Geography: Taking Cricket Fighting in Xi'an as an example
}

\author{
Xiaojun Yang ${ }^{1,2^{*}}$, Yiyi Wang ${ }^{1}$, Ziqi Kong ${ }^{1}$ and Xiuyuan $\mathrm{Li}^{1}$ \\ ${ }^{1} X i$ 'an International Studies University, tourism Academy.Institute of Human Geography, Xi'an, Shaanxi Province, 710128, \\ China \\ ${ }^{2}$ Shaanxi Tourism Research Institute, Xi'an, Shaanxi province, 710128, China \\ *Corresponding author. E-mail: yangxiaojun@xisu.edu.cn
}

\begin{abstract}
In the context of geographical "emotional turn", urban leisure began to pay attention to the locality reflected by the leisure subject and the "human-land relationship" of the city. This study takes Xi'an cricket fighting as an example, analyzes the coupling relationship between this leisure style and the local time and space by interpreting the local cognitive system and the local map of urban leisure, and using GIS analysis and in-depth interviews. It also reveals the spatial attributes, local meaning, and spiritual functions of urban leisure locality from three levels: material, social, and spiritual. The conclusions show that: (1) the attributes of nature, landscape and space reflect the material functions of urban leisure locality. (2) historical, cultural, institutional, and social aspects reflect the social functions of urban leisure locality, and also reflect the local consciousness and life characteristics. (3) The urban culture reflected by leisure style and life pursuit embodies the spiritual function of urban leisure locality.
\end{abstract}

Keywords: Emotional geography; Urban leisure; locality; Xi'an; Cricket fighting

\section{INTRODUCTION}

"One water live one people." Different regional cultures give birth to leisure methods with different local characteristics. In this sense, urban leisure has become a symbol of urban regional culture and local memory because of its strong local colors and local characteristics. In the process of urban development, with the emphasis on cultural soft power and the deepening of local research, the locality of urban leisure has become the current focus of attention.

As Western social sciences and humanities paid great attention to the study of emotions and the influence of cultural geography "spatial turn", geography began to notice the effect of emotion on space and society, and triggered the "emotional turn" of geography [1].The research content mainly focuses on environmental changes, sense of place, intimate space, politics, education, race and minority topics [2]. Davidson and Rowel focus on the impact of places on human emotions [3-4]. In this context, Tuan introduced the concept of "place" into human geography [5].With the continuous deepening of local research abroad, Chinese scholars have conducted in-depth discussions on locality from different perspectives. Zhou Shangyi analyzed the locality from the perspective of cultural geography. She pointed out that the definitions of locality by humanism and structuralism are similar in nature, and all refer to the specificity of a
place[6].Gao Quan and Qian Junxi studied the local reconstruction of Liede Village from the perspective of emotional geography, affirming the importance of emotion in the construction of social and cultural space [7].

Due to the in-depth study of space in geography and the focus of leisure research on people, there is a clear cultural and emotional shift in the study of leisure in the geography community. Foreign scholars pointed out that community gardens, as a kind of urban leisure space, not only improve the quality of life of community residents, but also help strengthen the communication between neighbors and enhance the residents' sense of local identity [8-9]. Chinese scholar Han Guangming introduced the local theory to urban leisure, and provided a new perspective for local research in the leisure field [10], Subsequently, The geographical field conducted in-depth discussions on "urban suburb development zones", "rural new immigrants", "folk festivals" and other localities [11-13]. Emotional geography provides an effective tool for explaining the phenomenon of "there is a special connection between man and ground", which has become an innovative and important theoretical method for studying urban leisure.

In summary, most domestic and foreign scholars' research on urban leisure focuses on material space. Local studies on urban leisure mostly use urban parks, communities, and historical blocks as examples to analyze the local emotional attachment or local identity of a specific group of people. However, there is a lack of a specific way of leisure as an example to study the local genes and external 
characteristics of urban leisure. Therefore, on the basis of predecessors, this study explores the local characteristics of urban leisure in xi 'an by building a local cognitive system and mapping of urban leisure to enrich the value of local in urban development.

\section{ANALYSIS OF THE RELATIONSHIP BETWEEN URBAN LEISURE AND LOCALITY}

\subsection{Analysis of local cognitive system}

Locality is a characteristic of a place that is different from other places. Based on previous studies, this paper summarizes and reorganizes the local cognitivecomposition system (Figure 1), including the material level, social level, and spiritual level. Among them, the material level (the object level) is the lowest level of the human-land relationship behavior system, usually referring to the four attributes of nature, matter, landscape and space. These four attributes are the combination of local physical material space and environment. In addition to the basic survival materials needed for human survival, it also includes the pursuit of multiple types of material elements by different cultural groups in the local area, such as historical blocks, places, and landscapes. The social level refers to the four attributes of culture, system, history, and society, and also refers to the functional attributes of daily life spatial behavior. The spiritual level is the highest level of the human-land relationship behavior system, carrying the subject's local identity and local emotional belonging, and always reproducing the social relationship itself.

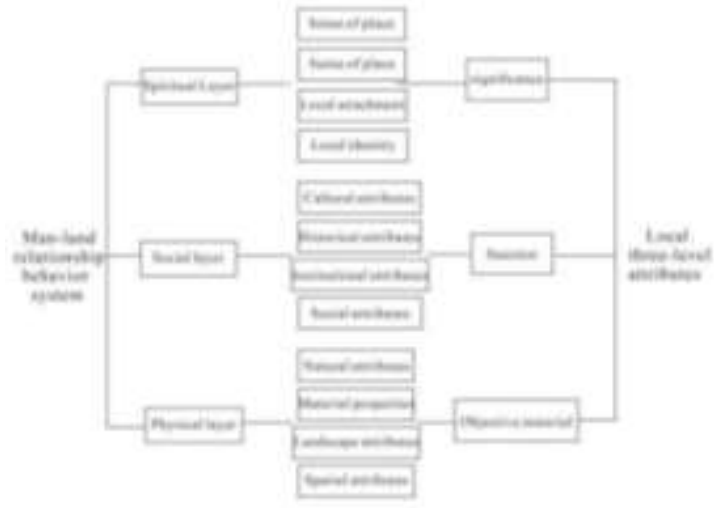

Figure 1 Local Cognitive Composition System Diagram

\section{2. analysis of the local map of urban leisure}

From the perspective of cities, due to the differences in natural ecological environment, geographical location, climate characteristics, cultural background and folk customs, each city has its own unique local characteristics. The essence of urban leisure is derived from the understanding, recognition and perception of the leisure subject to the city through its leisure means. This paper refers to Zhang Zhonghua's urban leisure local view and the local cognitive architecture diagram analyzed above as the theoretical basis.

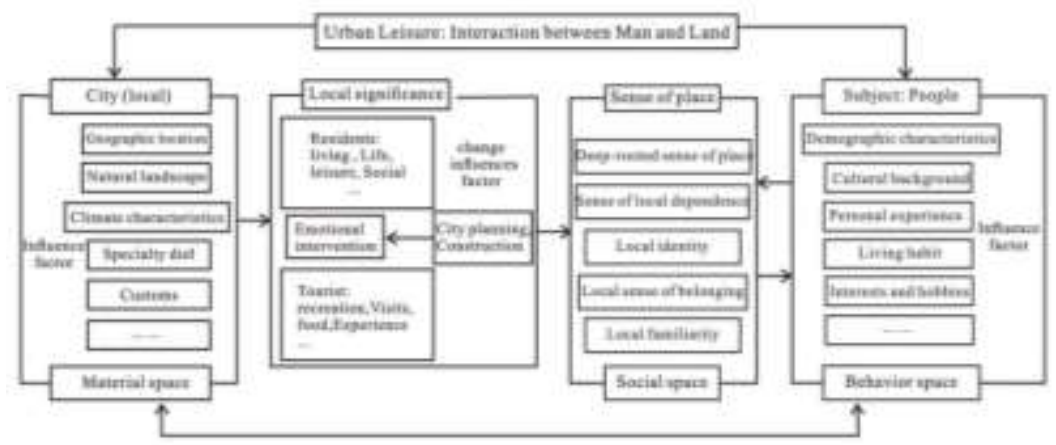

Figure 2 Framework of Urban Leisure and Local Studies

As shown in Figure 2, the city is a space full of meaning. Places (city), urban leisure subjects (residents), local meaning and sense of place constitute a framework for urban leisure and local research. (1) Different objective material attributes of the city create local material functions with different styles. The impression, understanding, emotion and perception of the city by the urban residents are the local social functions endowed to the city.(2)Urban leisure subjects have a local sense of identity and belonging to the city through emotion, cognition, and behavior. At the same time, local cognition is formed according to demographic characteristics and cultural background, reflecting different urban social spatial subjects; (3) urban residents The local spiritual significance of is mainly reflected in its daily life such as living, leisure, socializing, etc., reflecting the local inherent characteristics of urban leisure.

The residents of each city have their own leisure methods. Although the drastic urbanization reform has made the localized urban leisure personality gradually decline or even die, there are still some local leisure methods that represent the city, such as the teahouse mahjong in Chengdu, the game of walking birds in Beijing, the cricket fighting in Xi'an. 


\section{THE STUDYING AREA AND RESEARCH METHODS}

\subsection{The studying area}

$\mathrm{Xi}$ 'an is a famous historical and cultural city with a history of over 3,100 years. The profound cultural accumulation makes Xi'an have its own unique urban regional culture. Since the Tang Dynasty, there have been 36 kinds of leisure activities similar to those of today. The more famous ones include Cuju, polo, pitching, and cricket, which laid the regional characteristics of Xi'an urban leisure. With the changes of the times, these traditional leisure methods have gradually disappeared in the long river of time. At present, only the leisure method of the cricket fighting is still circulating to this day.

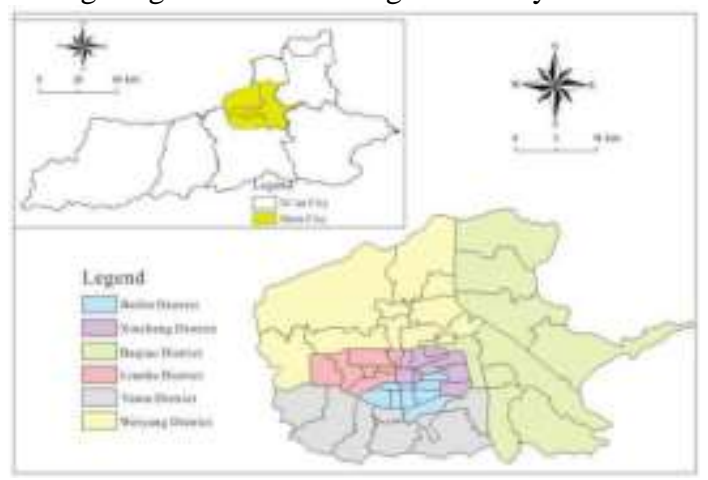

Figure 3 Location Map of Xi'an Main City

\subsection{The research method}

\subsubsection{GIS dimensional analytic method}

Through literature reading and field survey data, and finally using GIS spatial analysis method to study the spatial and temporal evolution of leisure mode, to explore the evolution process of this ancient leisure mode in the rapid social development.

\subsubsection{In-depth interview}

The team conducted a two-month survey in June 2018 and July 2018 in the surrounding area of the City God Temple and $\mathrm{Xi}$ Cang in the main city of Xi'an, interviewing 87 local residents of Xicang, 6 vendors and 12 players, Including 61 men, aged between 12-79 years old. A total of 67 effective recordings were obtained. The interview time is mainly between $0.5-1.5$ hours. Researchers used local dialects and used old photos to make residents naturally express emotions in interviews. The contents of the interviews in this study mainly focus on three aspects: (1) how urban leisure reflects locality through its material level (including nature, material, space, etc.); (2) how urban leisure starts from the social level (including history, culture, Institutions, society, etc.) characterize locality; (3) How does leisure behavior affect residents' local emotions or leisure styles and what significance does it have in the local construction of residents.

\section{SPATIO-TEMPORAL COUPLING ANALYSIS OF CRICKETS IN XI'AN CITY}

The Chinese cricket culture has a long history. It is a unique cultural life in China with strong oriental colors, and it is also Chinese art. The earliest attention was given to the cricket because it has a typical phenological feature. The so-called "cricket sounds, sluts startled" proverb, so also known as "cu zhi". Cricket fighting is an entertainment and leisure activity in ancient times. It is one of the folk fighting games of the Han nationality.

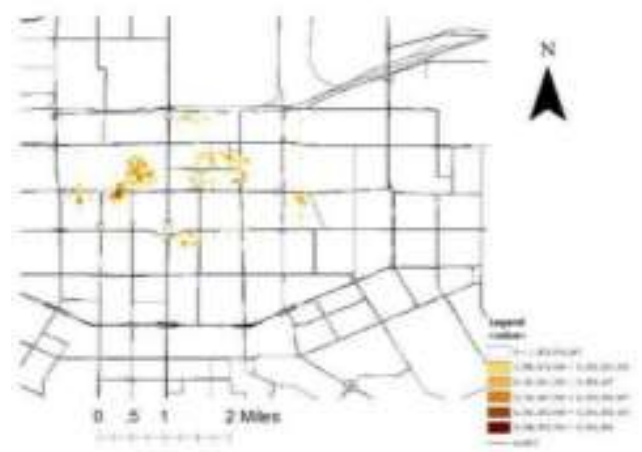

Figure 4 Cricket Fighting in Tang Dynasty

At present, among the five northwest provinces, only Shaanxi still retains this traditional way of leisure. According to the content of the interviews and the literature, GIS software was used to draw the main distribution areas of cricket fighting in the Tang and Ming Dynasties. Through the analysis of the cricket place and the change of the crowd, we dig out the locality of cricket fighting cricket leisure way.

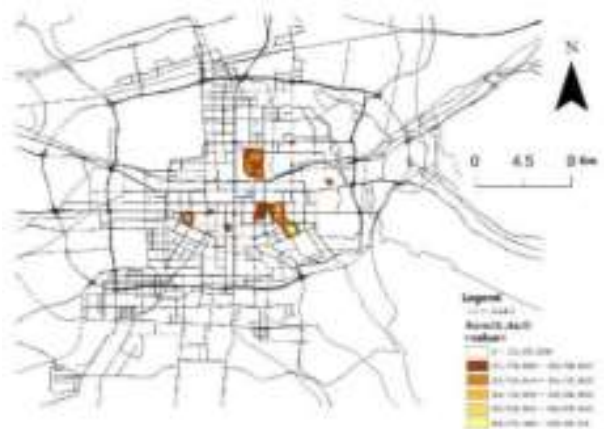

Figure 5 Cricket Fighting in Ming Qing Dynasty 


\subsection{Spatial and temporal evolution analysis of leisure space (material function)}

Cricket fighting leisure space evolution reflects two levels of meaning: cricket fighting place from the official living space to the public living space penetration trend; The natural attributes, material attributes, landscape attributes and spatial attributes of leisure behavior have not changed significantly.

As shown in Figure 4, during the Tang Dynasty, the cricket leisure methods were mainly distributed in three areas: Xingqing Palace East City, West City and Northeast Chang'an City are distributed in a plane. During the Tang Dynasty, there was no concentrated cricket fighting place for the citizens. The crickets fought by the citizens were caught by themselves. Most of them were scattered sporadically along rivers and fields, covering their living, working and living space. During the Ming and Qing Dynasties, the main venues of Xi'an crickets fighting were the Qing Eight Banners school ground and the Qing generals, Yong Feng warehouse and Cheng Huang temple. In the early years of the Republic of China, Xicang (Yongfeng cang) developed greatly. The city of Birds and Insects grew in size, and the service target was expanded from the original service for the banner people to the flowers, birds, insects and fish lovers in the city. It has been retained until now. At present, the ancient leisure method of crickets fighting is mainly concentrated in the Xicang market (Figure 6 and Figure 7).

"... E(I) used to set up a stall on West Street, but later I won't let it stand, so E (I) come here ..."

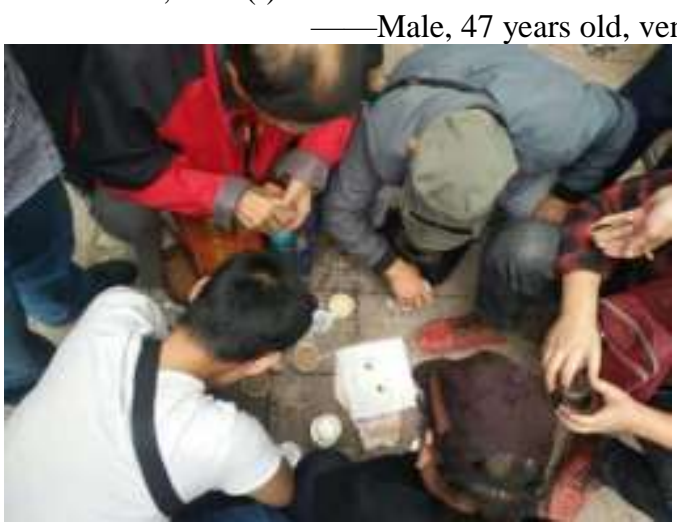

Figure 6 Cricket Fighting in Xi'an

On the other hand, although the spatial scope of leisure behavior is constantly changing, its spatial elements have not changed. In terms of natural attributes, the ancient cricket's appearance has been good or bad, the price differs from a few to ten thousand yuan. In terms of material properties, the crickets fighting is generally used as a cricket grass, also known as goosegrass. The utensils for feeding and crickets fighting are called cricket pots (cricket pots), and they are made of porcelain, pottery (clay), and jade. In terms of spatial attributes, the places where the crickets fighting from the Tang Dynasty to the Qing Dynasty were outdoor open spaces, such as courtyards, streetsides, and markets; Since the Republic of China, it has also concentrated on outdoor leisure spaces such as markets, streets, and parks.

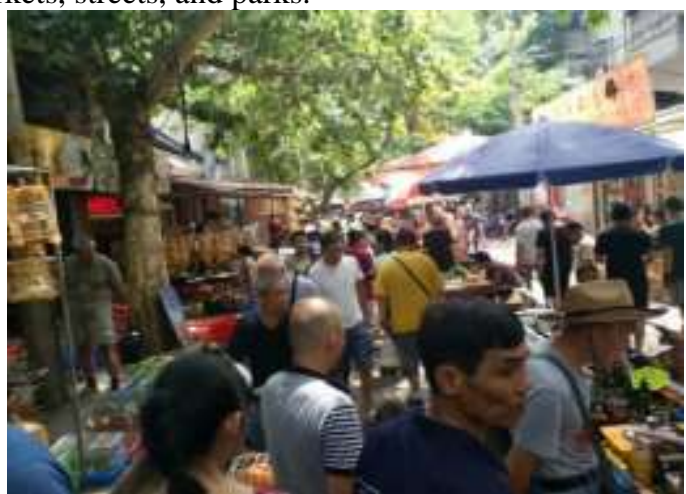

Figure 7 Xi Cang Market

"... I used to go to Cheng Huang Temple and the east of the city, but now I often come here. Although there are fewer places to fight crickets now, coming to Xicang is like finding an organization. You don't need to ask, it's definitely our old Xi'an. Fortunately, this place is still there, otherwise we have no place to go ..."

-Male, 61 years old, player

\subsection{The analysis of local identity of leisure subjects}

The cricket fighting reflects changes in the social class. The transformation of leisure subjects from aristocratic class to civic class shows that fighting cricket is a popular way of leisure and a social fashion at that time.

"... I'm retired now, and it's okay. I like to go to Xicang in the summer. A large group of people squatted around a jar. Not to participate, but it's fun to watch. You see, it's old men like us, and who are young boys to come here..."

Male, 72 years old, retired worker In terms of cultural attributes, the cricket fighting inheritance has formed a representative Chinese cricket culture. In terms of institutional attributes, the leisure activities of the cricket fighting always follow the same rules. In Xicang, some traders still make a living and enjoy it.

"... this jar is not for sale, it was recovered last year, and the figure of the figure is carved on it. This jar is specially collected and will not be taken out ..."

-Male, 61 years old, vendor "... My family lives nearby, and I don't have any sideline business, so I sell the cricket to make a living. Selling cricket is the career of several generations of people in the family, and it doesn't say how much money you make, just because I like..."

-Male, 52 years old, vendor Due to different social and cultural attributes, the different ways in which the subject participates in leisure has shaped the local identity of leisure behavior. Through different ways of participation, the cricket fighting is given a unique local meaning. 
"... Xicang market has a lot of elderly people, and there are very few women on the street where crickets are sold. But I heard that the most powerful cricket in Xi'an is still a woman, who can earn hundreds of thousands of dollars a year. We're all here to join in the fun, and usually there's more going along than fighting..."

—male, 45 years old, player

\section{3. spatial and temporal coupling analysis of mental space (leisure behavior space)}

When the meaning of the place is impacted, people restore their homes through emotional sustenance, and leisure behavior becomes an important way, including residents' local attachment, local identity and other emotions. It reflects the meaning of three levels:

First, leisure behavior reflects the way of life of urban residents, is the perception and understanding of life of urban residents. Dating back to ancient times, the "Book of Songs" has repeatedly expressed the poet's emotions with the theme of crickets, extolling and admiring the exuberant and strong vitality, sighing for life and missing the hometown. Nowadays, Xicang cricket fighting is the epitome of Xi'an's leisure culture, and it reflects the local lifestyle of residents in a certain degree.

Second, leisure behavior embodies the characteristics of urban leisure and has a certain impact on leisure subjects. Cricket fighting as a way of leisure brings the spiritual sustenance of Xi'an.

"... Summer time, I will often take time to come here, although not fighting cricket, but can squat with you see, after the end, find a stool to listen to the crickets' cries, don't mention how comfortable. I work in the high-tech industry and work hard as a programmer. This is indeed a unique condiment for me ..."

Male, 39 years old, programmer "...I usually work in a company, and I will come here to play on weekends ... I don't have much money for a month's salary, but I think how much money I earn is enough to spend, and happiness is most important. Cricket, I am very happy even watching others fight ... "

Male, 35 years old, player Third, leisure culture penetrates into the local characteristics of the city, reflecting the urban temperament and cultural heritage. Its protection is rooted in the traditional regional culture, which fully reflects the relationship between the people of Xi'an and the ancient city of Xi'an. The retention and continuation of the fighting cricket in Xicang reflects the profound local emotions established between people and cities in this leisure style, and this emotion also affects people's leisure behaviors.

"... The travel agency has begun to build a one-day tour of Xicang. Taking tourists to cricket fighting will give them a feeling of being a real Xi'an. Don't underestimate the cricket fighting, it has been integrated into the way of life of our people in Xi'an, blending our emotions and representing Xi'an. If Huimin Street is the business card of
Xi'an City, then Xicang is completely called "Xi'an Encyclopedia of Folk Culture ..."

Female, 27 years old, tour guide This way of leisure is rooted in Xicang, which has the culture of Xi'an city. The spread of thousands of years has developed into the most leisure mode that reflects the characteristics of Xi'an city. It embodies the local culture and leisure characteristics of this ancient city of Xi'an, shaping Xicang's unique local leisure space, and constantly enhancing people's local identification with Xicang.

\section{CONCLUSION AND DISCUSSION}

The regionality of a city is the gene and root of a city and the background of its long-term development. In the process of the emergence and development of cities, through the evolution and continuation of history, each city has formed its own locality of urban leisure.

The locality of Xi'an urban leisure is embodied in three levels: material, social and spiritual. Materially, the Xicang market in the old city is not only the main place where leisure activities are concentrated, but also an important carrier for the local establishment of the city. At the social level, the locality of residents' leisure behaviors is shown from the historical, institutional and social perspectives. the cricket fighting reflects the changes in the social class, reflecting the local leisure characteristics of Xi'an.The spiritual level carries the local emotions of the residents. the leisure behaviour reflects the way of life of urban residents and the characteristics of urban leisure, and they reflect the local culture and heritage of Xi'an city.

With the continuous advancement of urbanization, the transformation and replacement of urban space makes the spatial texture fragmented, local memory and leisure functions weaken, and the traditional leisure methods retained in the lives of residents continue to exist and are rooted in the spiritual life of residents, reflecting the city Cultural and local characteristics. In the future urban development, paying attention to and tapping the locality of urban leisure will contribute to the sustainable development of the city and enhance the city's soft power.

\section{ACKNOWLEDGMENT}

The research was supported by Shaanxi social science community 2019 major theoretical and practical issues research project (2019C131), Xi'an International Studies University Graduate Research Fund Project (SYJS201806).

\section{REFERENCES}

[1] Liang, L., Dai, L., Tian, J.S. (2018) The characteristics of tourist experience in memorial landscapes of fear from the perspective of emotional 
geography: The case of $5 \cdot 12$ Wenchuan Earthquake Memorial Museum.J. Journal of Northwest University (Natural Science Edition), 48(06):884-892.

[2] Zhu, H., Gao, Q. (2015) Review on "emotional turn" and emotional geographies in recent western geography. J. Geographical Research., 34(07):1394-1406.

[3] Davidson, J., Bondi, L. (2005) Smith M. Introduction: Geography's 'emotional turn'. In: Davidson, J., Bondi, L., Smith, M., Emotion-al Geographies. J. Burlington VT and Aldershot: Ashgate. pp.1-16.

[4] Rowles, G. (1978) The Prisoners of Space? Exploring the Geo- graphical Experience of Older People. J. Boulder CO: Westview.

[5] Tuan, Y. F. (1977) Space \& Place: The Perspective of Experience. Minneapolis: University of Minnesota Press., 1-17.

[6] Bai, K., Zhou, S.Y., Lv, Y.Y. (2014) The progress of social cultural geography in China in recent 10 years. J. Acta Geographica Sinica., 69(08):1190-1206.

[7] Gao, Q.,Qian, J.X.,(2016) Negotiating piace-restructuring form the perspective of emotional geographies:A case study of liede villang Guangzhou. J. Human Geography., 31(04):33-41.

[8] Drake, L., Lawson, L. J. (2014) Validating verdancy or vacancy? The rela- tionship of community gardens and vacant lands in the US. J. Cities., 40: 133 - 142.

[9] Kemperman, A., Timmermans, H. (2014) Green spaces in the direct living environment and social contacts of the aging population. J. Landscape and Urban Planning., 129: 44-5.

[10] Han, G.M., Huang, A.M., (2013) Exploration of applying place theory to urban-based leisure study. J. Human Geography., 28(02):125-130.

[11] Kong, X., Chen, D. (2016) The influence of suburban development zones on deconstruction of placeness of the host regions: A case of Changsha economic and technological development zone. J. Human Geography., 31(04):26-32.

[12] Jin, R.W., Gong, B. L. (2017) A Study on the Sense of Place of "New Rural Migrants" —_Based on the Empirical Investigation in Zhejiang Province. J. Journal of Tianjin Normal University (Social Science)., 06:61-65.

[13] Tao, W., Chen, H.L., Cai S.Q. (2014) Influence of
Lingnan traditional folk festival reconstruction on resients' place attachment:A case study on Qiqiao Festival in Guangzhou Zhucun. J. Acta Geographica Sinica., 69(04):553-565. 